Stephen Kowalski MD FRCPC, Allen R. Downs MD FRCsC Facs, Charles Lye MD FRCSC, Luis Oppenheimer MD FRCSC FACS

\title{
Measurement of extra- vascular lung water during abdominal aortic surgery
}

\begin{abstract}
Cross-clamping of the abdominal corta can be associated with significant changes in haemodynamic variables. However, intraoperative changes in extravascular lung water (EVLW) have not been studied. Nine patients undergoing elective surgery, either aortic aneurysm repair or aorto-bifemoral grafting, were monitored invasively with arterial lines, pulmonary artery cathesers and Edwards lung water catheters inserted in either the brachial or axillary artery. Determinations of $E V L W$ were made prior to and five minutes after application of the aortic cross-clamp and at 30-minute intervals during the course of the operation. Baseline EVLW was found to be $7-9 \mathrm{ml} \cdot \mathrm{kg}^{-1}$. There were no significant changes in haemody. namic variables and no changes in EVLW with cross-clamping of the aorta. The EVLW did not change during the course of surgery. The EVLW did not increase in the absence of sustained elevation of pulmonary capillary wedge pressure. One patient developed an axillary artery thrombosis which required thrombectomy at the site of lung water catheter insertion. Two other patients lost their distal pulses without overt ischaemic changes. It was felt that such relatively high incidence of complications precluded further use of the lung water catheter in the axillary or brachial artery.
\end{abstract}

\section{Key Words}

ANAESTHESIA: cardiovascular; LUNG: oedema; MEASUREMENT TECHNIQUES: lung water; SURGERY: vascular aorta, aneurysm.

From the Departments of Surgery and Anaesthesia, University of Manitoba

Address correspondence to: Dr. S. Kowalski, GA709, Health Sciences Centre, 700 William Avenue, Winnipeg, Manitoba R3E 0Z3.

Dr. Kowalski is a fellow of the Manitoba Lung Association. Dr. Oppenheimer is a Myles Robinson Scholar. Work supported by grants from the Medical Research Council of Canada.
Elective surgery on the abdominal aorta has become increasingly safe, but the reported perioperative mortality rate is still three to eight per cent. ${ }^{1-5}$ Most of the deaths are related to perioperative myocardial infarction and congestive heart failure. There is a high incidence of coronary artery disease, even in clinically asymptomatic patients. Attia et al. studied patients undergoing abdominal aortic surgery and described two different haemodynamic responses to aortic cross-clamping. ${ }^{6}$ One group responded with an increase in pulmonary artery pressure, pulmonary capillary wedge pressure and central venous pressure; whereas the other group showed decreases in these pressures.

The response of extravascular lung water to aortic cross-clamping has not been studied clinically. If the pulmonary capillary wedge pressure increases significantly, there may be increases in lung water which may not resolve immediately. Previous work in our laboratory, in dogs, has shown a marked hysteresis in the formation and resolution of pulmonary oedema: Resolution of pulmonary oedema was delayed, taking up to eight hours to return to baseline conditions. ${ }^{7}$ The purpose of this study was to determine if extravascular lung water changed with aortic cross-clamping and whether there is hysteresis in the formation and resolution of excessive lung water in humans.

\section{Methods}

Hospital human studies approval and informed written consent from each patient were obtained. Nine patients (four women and five men) ranging in age from 44-73 years and admitted for elective abdominal aortic surgery were studied. Patients with a history of Raynaud's disease or thrombo-embolic disease to the arms were excluded from the study. Patients were not pre-selected for factors that might predispose to left ventricular failure or pulmonary oedema. The various risk factors are shown in Table I.

None of the patients was taking medications for congestive heart failure. One patient, No. 6, had experienced two myocardial infarctions; the most recent one being two years before surgery. One patient had experi- 
TABLE I Patient population

\begin{tabular}{|c|c|c|c|c|c|c|c|c|c|}
\hline & Age & Sex & Hypertension & Smoker & $M I$ & $C H F$ & AbHormal ECG & Angina & Diabetes \\
\hline 1 & 57 & $F$ & $x$ & - & - & - & $\mathrm{X}$ & $\mathrm{X}$ & - \\
\hline 2 & 44 & $F$ & $X$ & $\mathbf{X}$ & - & - & - & - & - \\
\hline 3 & 59 & $\mathrm{M}$ & - & $x$ & - & - & - & - & - \\
\hline 4 & 63 & $\mathrm{M}$ & - & $x$ & - & - & $\mathrm{x}$ & - & - \\
\hline 5 & 61 & $\mathbf{M}$ & - & $\mathbf{X}$ & - & - & $\mathrm{x}$ & - & - \\
\hline 6 & 74 & $\mathbf{F}$ & $\mathbf{X}$ & - & $\mathrm{x}$ & - & $\mathrm{x}$ & $x$ & $x$ \\
\hline 7 & 67 & $M$ & - & $\mathbf{x}$ & - & - & $\mathrm{X}$ & - & $\mathrm{x}$ \\
\hline 8 & 60 & $\mathbf{M}$ & - & $\mathrm{X}$ & $\mathrm{X}$ & - & - & - & - \\
\hline \multirow[t]{3}{*}{9} & 70 & $\mathbf{F}$ & $\mathbf{X}$ & $\mathbf{X}$ & - & - & $\mathrm{x}$ & - & - \\
\hline & - & & - & - & - & - & - & - & - \\
\hline & 61.7 & & 4 & 7 & 2 & 0 & 6 & 2 & 2 \\
\hline
\end{tabular}

enced one myocardial infarction and five patients had nonspecific $T$ wave changes on their electrocardiogram. Two patients had stable, well controlled angina only on moderate to severe exertion. Three patients were hypertensive, two had non-insulin dependent diabetes mellitus and six were cigarette smokers. Three patients had repair of abdominal aortic aneurysms and six had aortobifemoral bypass grafts.

All patients were seen and given premedication as per the anaesthetist for the case. On arrival in the operating room, four ECG limb electrodes were attached and a left radial arterial line and a pulmonary artery catheter were inserted. In addition, a \#5 French Edwards Lung water catheter was inserted in either the right brachial or axillary artery. The femoral artery could not be used because of the aortic cross-clamp. All pressures were recorded on a Hewlett Packard 7758B, 4 channel recorder. All catheters were inserted under local anaesthesia prior to the induction of general anaesthesia.

Extravascular lung water (EVLW) was determined with an Edwards lab model 9310 lung water computer using the double indicator dilution technique. This method uses two indicators, temperature and indocyanine green, which are injected simultaneously into the right atrium via the proximal port of the pulmonary artery catheter. Indocyanine green binds to albumin and remains intravascular whereas temperature acts as the extravascular indicator by diffusing freely to mix with extravascular water in the lung while passing through the pulmonary capillaries.

The indicators are then detected in the aorta or one of its branches. The thermistor in the lung water catheter detects temperature changes. Green dye concentration is measured using a densitometer and cuvette. The cuvette is attached to the lung water catheter and at the time of lung water measurement, blood is withdrawn through it using a withdrawal/infusion pump at a rate of $30 \mathrm{ml} \cdot \mathrm{min}$. The densitometer then measures green dye concentration.

Analysis of the indicator dilution curves allows calcula- tion of cardiac output as well as the mean transit time for each indicator. The product of mean transit time and cardiac output for a given indicator yields the volume of distribution of that indicator. The difference between the distribution volumes of the two indicators represents the volume of extravascular water in the lung.

Anaesthetic technique was not standardized for this group of patients. Anaesthesia was induced with a combination of thiopentone and fentanyl. The trachea was intubated after paralysis with either succinylcholine or pancuronium and anaesthesia was maintained with oxygen, nitrous oxide, fentanyl and either halothane or isoflurane. Vasopressors and vasodilators were administered as necessary by the anaesthetist. The actual drugs and dosages used varied with the individual anaesthetist.

Determination of EVLW and cardiac output (CO) were performed prior to and just after the induction of anaesthesia in four patients. In all patients EVLW and CO were measured prior to and five minutes after cross-clamping of the aorta. These variables were measured every 20-30 minutes thereafter until the end of surgery. All other haemodynamic variables, blood pressure (BP), pulmonary artery pressure (PAP), right atrial pressure (RAP) and pulmonary capillary wedge pressure (PCWP) were measured at the time of EVLW determination. Cardiac outputs were determined with the Edwards lung water computer by analysis of the thermodilution curve. Neither the anaesthetist nor the surgeon was aware of the EVLW measurements and neither drug therapy nor fluid administration was altered because of lung water values.

It was thought that such a study might make an anaesthetist more cautious in his/her fluid administration. The amount of intravenous fluid given to the study group was compared with that given to a control group which consisted of all patients having aortic surgery in the six months preceding the study.

Statistical analysis of EVLW, CO and PCWP was done using one-way analysis of variance. Tukey's range test for repeated measures was used to identify significant differ- 


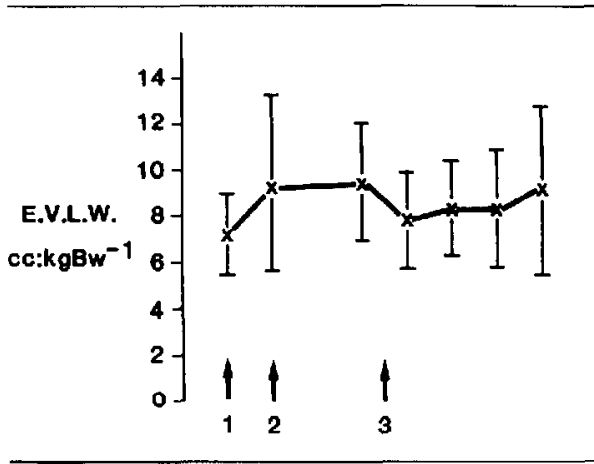

FIGURE 1 Induction of araesthesia. (1) Pre-induction; (2) postinduction; (3) application of aortic cross-clamp.

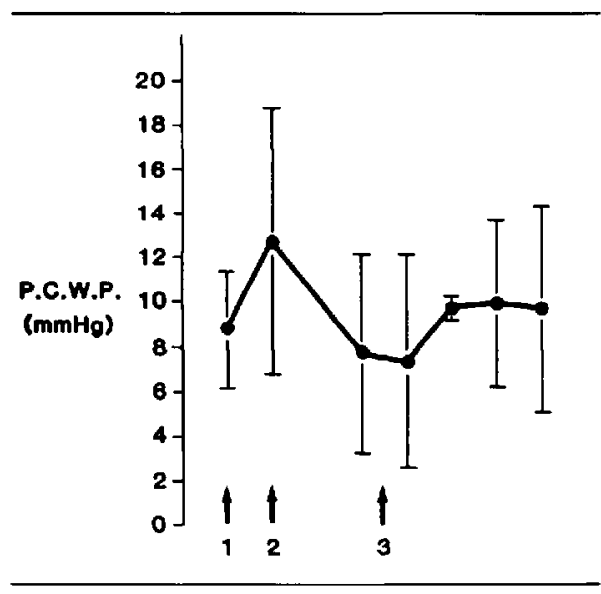

FIGURE 2 Aortic cross-clamping. (1) Pre-induction; (2) postinduction; (3) application of aortic cross-clamp.

ences. Haemodynamic variables prior to and just after application of the aortic cross-clamp were compared using a paired student's T-test. A P value of $\leqslant 0.05$ was considered statistically significant.

\section{Results}

Values for extravascular lung water, pulmonary capillary wedge pressure and cardiac index during the course of surgery are shown in Figures 1,2 and 3 respectively.

\section{Induction of anaesthesia}

With induction of anaesthesia there was a statistically significant decline in cardiac index $\left(4.42 \mathrm{~L} \cdot \mathrm{min}^{-1} \cdot \mathrm{m}^{-2}\right.$

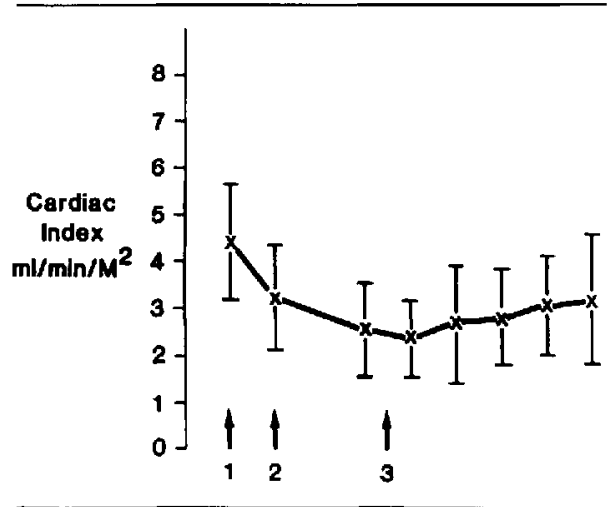

FIGURE 3 Complications of insertion of lung water catheter. (1) Pre-induction; (2) post-induction; (3) application of aortic crossclamp.

to $3.23 \mathrm{~L} \cdot \mathrm{min}^{-1} \cdot \mathrm{m}^{-2}$ ). There was a tendency for PCWP and EVLW to increase but these changes did not achieve statistical significance. Other haemodynamic variables did not change significantly.

\section{Aortic cross-clamping}

In response to aortic cross-clamping, EVLW decreased in all patients from a mean of 9.50 to $7.85 \mathrm{ml} \cdot \mathrm{kg}^{-1}$, but this did not reach statistical significance. No other haemodynamic variable changed significantly. Blood pressure, heart rate, cardiac index, pulmonary artery pressure, PCWP, and right atrial pressure were not altered by cross-clamping of the aorta. The mean results are shown in Table II. During the remainder of the surgery, there were no significant changes in EVLW, $\mathrm{CI}$ or PCWP. No patient developed a sustained increase in PCWP. The average amount of intravenous fluids given to study patients was $44.0 \mathrm{ml} \cdot \mathrm{kg}^{-1}$. The control group received $36 \mathrm{ml} \cdot \mathrm{kg}^{-1}$. These were not significantly different.

TABLE 11 Haemodynamic response to infra-renal aortic crossclamping

\begin{tabular}{lcc}
\hline & Pre-clamping & $\begin{array}{l}\text { Post-ciamping } \\
(5 \text { min })\end{array}$ \\
\hline $\begin{array}{l}\text { Mean systemic blood pressure } \\
\quad(m m H g)\end{array}$ & $95 \pm 15$ & $108 \pm 30$ \\
PAP & $15.8 \pm 3.8$ & $14.75 \pm 4.26$ \\
PAP & $6.0 \pm 3.2$ & $5.25 \pm 2.25$ \\
PCWP & $7.75 \pm 4.4$ & $7.37 \pm 4.77$ \\
Cardiac index L $\cdot \mathrm{min}^{-1} \mathrm{~m}^{-2}$ & $2.59 \pm 9.7$ & $2.42 \pm .76$ \\
EVLW $\mathrm{ml} \cdot \mathrm{kg}^{-1}$ & $9.5 \pm 2.55$ & $7.85 \pm 2.09$ \\
\hline
\end{tabular}

All results are mean $\pm \mathrm{SD}$. 
Complications of insertion of lung water catheter

There was a number of complications associated with the use of the lung water catheter. The catheter was difficult to insert without the use of a vessel dilator. All patients had large haematomas at the site of the catheter insertion. One patient developed an axillary artery thrombosis and had a cold, blue hand. This required surgical exploration and correction and the patient subsequently did well. Two other patients lost their distal pulses postoperatively but did not have ischaemic hands. The pulses returned spontaneously within 24 hours.

\section{Discussion}

Cross-clamping of the aorta can be associated with major changes in systemic haemodynamic variables. ${ }^{6.8,9}$ Attia et al. were able to divide patients into two groups depending on the changes in pulmonary capillary wedge pressure, pulmonary artery pressure and central venous pressure. ${ }^{6}$ One group had decreases in these pressures, whereas the other had increases. Elevation of PCWP of 7 $\mathrm{mmHg}$ or more was associated with evidence of myocardial ischaemia and sodium nitroprusside was used to reverse the elevation of PCWP and the changes of myocardial ischaemia. All of these patients were known high-risk patients with history of previous myocardial infarction, previous coronary artery surgery, or congestive heart failure. All the low-risk patients, with negative cardiac history and normal ECG responded with a decrease in central pressures. Gooding et al. found that patients with a history of coronary artery disease responded to application of the aortic cross-clamp with a decrease in $\mathrm{Cl}$ and an increase in PCWP ${ }^{8}$ Patients without a history of coronary artery disease had decreases in $\mathrm{CI}$ and PCWP when the aorta was cross-clamped. Meloche et al. described a group of 18 patients having aortic surgery, all of whom developed an increase in systemic vascular resistance and a decrease in CI with cross-clamping of the abdominal aorta. ${ }^{9}$ Details were not given of the patients' preoperative status and PAPs were not measured.

Recognition of the potential adverse effects of aortic cross-clamping and declamping has led to the increasing use of invasive haemodynamic monitoring to optimize volume loading and the use of vasopressors and vasodilators to manage the haemodynamic changes that occur.

In this group of patients there were no significant changes in any haemodynamic variable with crossclamping of the aorta. The patients could not be divided into two groups as has been done in previous studies. Patients having resection of abdominal aortic aneurysms did not differ from those having aorto-bifemoral grafts in their haemodynamic responses. This is probably not surprising considering that these patients were not preselected to be at high risk. Also, most importantly, they were all monitored with PA catheters. The anaesthetist in charge was not aware of lung water measurements but did have access to the PAP measurements and acted on adverse changes in them. There was one patient, \#6, who had a transient rise in PCWP from $10 \mathrm{mmHg}$ to $17 \mathrm{mmHg}$ during surgery. This change was not associated with cross-clamping of the aorta, and retumed to normal within minutes after administration of sodium nitroprusside. This transient increase in PCWP did not produce any measurable increase in EVLW. Thereafter the patient remained stable. Interestingly, 72 hours postoperatively this patient developed ECG evidence of myocardial ischaemia and pulmonary oedema. This occurred when the patient had been discharged to the ward and was not being invasively monitored.

Our baseline measurements for EVLW are in the range of $7-9 \mathrm{ml} \cdot \mathrm{kg}^{-1}$. This is higher than the range generally reported in man, $5.5-6.5 \mathrm{ml} \cdot \mathrm{kg}^{-1} \cdot{ }^{10-12,15}$ Gravimetric measurements of EVLW in animals are in the range of 6-7 $\mathrm{ml} \cdot \mathrm{kg}^{-1} \cdot{ }^{14}$ Thermodilution measurement of EVLW has been reported to both over- and underestimate lung water in a number of clinical circumstances. Haemodynamic factors, specifically a decrease in $\mathrm{CO}$, have been shown to cause an overestimation in EVLW. Fallon et al. demonstrated that a 50 per cent decrease in $\mathrm{CO}$ caused a 40 per cent overestimate of lung water. ${ }^{16}$ Perfusion defects in the pulmonary circulation, caused by glass bead or air emboli can cause underestimation of lung water ${ }^{12}$

Positive end-expiratory pressure (PEEP) has also been shown to affect lung water determination. Application of PEEP may decrease perfusion to certain lung zones by creating Zone I conditions and thus decrease EVLW. Alternatively, it may increase perfusion to localized areas of injured lung and increase EVLW. ${ }^{12}$ Technical problems with the thermistor may also cause overestimation of lung water. Wesse ${ }^{13}$ has shown that there is a boundary layer of slowly moving blood that extends $1-2 \mathrm{~mm}$ from the arterial vessel wall. Thermistors positioned in this boundary layer record temperature curves with a delayed buildup and decay and consequently record a longer thermal transit time. This can give a larger thermal volume of distribution and lead to overestimation of EVLW. Placing the lung water catheter in the axillary artery in dogs has been shown not to change lung water measurements. Although there are a number of reasons for both over- and underestimation of ELVW, our results were consistent and did not show any change intraoperatively.

Extravascular lung water does not appear to increase significantly unless there are significant rises in PCWP. Byrick, Kay and Noble measured EVLW in patients undergoing aortocoronary bypass surgery. ${ }^{15}$ They found that there was no significant increase in EVLW immedi- 
ately after surgery in spite of large decreases in colloid osmotic pressure (COP) from 18.9 to $9.3 \mathrm{mmHg}$ during extracorporeal circulation. The one patient who did have a significant increase in EVLW had elevated PCWP, $>20$ $\mathrm{mmHg}$, during the pump run. In another study Gallagher, Moore et al. confirmed that EVLW does not change during coronary artery bypass grafting as long as PCWP is maintained less than $14 \mathrm{mmHg}$ in spite of different types of intravenous fluid administration. ${ }^{17}$

Shires et al. compared the effects of crystalloid versus colloid infusion in patients undergoing abdominal aortic surgery, ${ }^{18}$ in whom the PCWP was kept within $2 \mathrm{mmHg}$ of preoperative levels. No change was found in EVLW immediately after surgery in both groups compared with the preoperative measurements. This was in spite of large decreases in COP, from 20 to $12 \mathrm{mmHg}$, in the crystalloid group.

These clinical reports confirm experimental findings in animals in whom it is very difficult to produce an increase in EVLW by decreasing the COP alone. ${ }^{19,20}$ This is attributable to the fact that the changes in protein concentration equilibrate relatively quickly across the pulmonary capillary membrane - effectively negating one another and producing no net fluid flux. However, a decrease in COP does reduce the "margin of safety" when elevations in the pulmonary capillary pressure occur and reduces the critical pressure needed for oedema formation. ${ }^{21}$

There were no changes in EVLW in our study group probably because no patient developed a sustained elevation in PCWP. This may be caused by a number of factors including the absence of high-risk patients studied and the benefits of haemodynamic monitoring and appropriate therapeutic intervention.

The fact that EVLW did not change also implies that there were no changes in capillary permeability caused by aortic cross-clamping or declamping. The only haemodynamic change of note was a decrease in CI with induction of anaesthesia. This is not surprising as anaesthesia was induced in all patients with thiopentone and fentanyl and maintained with nitrous oxide.

There was a number of complications related to the use of the lung water catheter in the arms of patients. Firstly, the catheter was difficult to insert without the use of a vessel dilator. Secondly, all patients had large haematomas at the site of the catheter in spite of direct pressure being applied for 20 minutes after its removal. One patient had a cold, blue hand immediately after surgery. This necessitated surgical re-exploration and removal of an axillary artery thrombus. At the time of the thrombecto$\mathrm{my}$, it was noted that the axillary artery was very small almost hypoplastic - and that this probably predisposed to thrombus formation. Two other patients had loss of distal pulses in the arm in which the lung water catheter was inserted. However, there was no overt ischaemia and the pulses returned within 24 hours without therapy.

It was felt that this high incidence of serious complications precluded further use of the lung water catheter in axillary or brachial arteries.

In summary, extravascular lung water was found to be in the range of $7-9 \mathrm{ml} \cdot \mathrm{kg}^{-1}$ body weight. The EVLW did not change with cross-clamping of the abdominal aorta in the absence of significant changes in pulmonary capillary pressure.

\section{References}

1 Thompson JE, Hollier LH, Patman RD et al. Surgical management of abdominal aortic aneurysms: factors influencing mortality and morbidity - a 20 year experience. Ann Surg 1975; 181: 654-61.

2 Feede CW, Hobson RW. Rich NM. Surgical management of 100 consecutive abdominal aortic aneurysms. Am J Surg 1975; 129: 506-8.

3 Hertzer NR. Myocardial ischemia. Surgery 1983; 93: 97-100.

4 Hertzer NR. Fatal myocardial infarction following peripheral vascular operations. Clev Clin Quart 1982; 49; 1-2.

5 Young AE, Sandberg GW, Couch NP. The reduction of mortality of abdominal aortic aneurysm resection. Am J Surg 1977; 134: 585-90.

6 Attia RR, Murphy JD, Snider M, Lappas DG, Darling RC. Lowenstein $E$. Myocardial ischemia due to infrarenal aortic cross-clamping during aortic surgery in patients with severe coronary artery disease. Circulation 1976; 53 : 961-5.

7 Mayers I, Stimpson R, Oppenheimer L. Delayed resolution of high pressure pulmonary edema or capillary leak. Surgery (In press).

8 Gooding JM, Archie JP, McDowell H. Hemodynamic response to infrarenal aortic cross-clamping in patients without coronary artery disease. Critical Care Medicine 1980; 8: 382-5.

9 Meloche R, Pottecher T, Audet J, Dufresne O, Lepage $C$. Haemodynamic changes due to clamping of the abdominal aorta. Can Anaes Soc J 1977; 24: 20-34.

10 Minati $M$, Pistolesi M, Milne ENC, Giuntini $C$. Detection of lung edema. Critical Care Med 1987; 15: 1146-55.

11 Sibbald WJ, Warshawski FJ, Short AK et al. Clinical studies of measuring extravascular lung water by the thermal dye technique in critically ill patients. Chest 1983; 83: 725-31.

12 Allison RC, Carlile PV, Gray BA. Thermodilution measurement of lung water. Clinics in Chest Med 1985; 6: 439-57.

13 Wessel HU, Paul MH, James GW, Grahn AR. Limitations 
of thermal dilution curves for cardiac output determinations. J Appl Physiol 1971; 30: 643-52.

14 Gray $B A$, Beckett RC, Allison RC et al. Effect of edema and hemodynamic changes on extravascular thermal volume of the lungs. J Appl Physiol 1984; 56: 878-90.

15 Byrick $R J, K a y J C$, Noble WH. Extravascular lung water accumulation in patients following coronary artery surgery. Can Anaes Soc J 1977; 24: 332-4.

16 Fallon $K$, Drake $R$, Laine $G$, Gabel J. Effect of cardiac output on extravascular lung water made with the Edwards Lung Water Computer. Anaesthesiology 1985; 62: 505-8.

17 Gallagher JD, Moore RA, Kerns KD et al. Effects of colloid or crystalloid administration on pulmonary extravascular lung water in the postoperative period after coronary artery bypass grafting. Anesth Anal 1985; 64: 753-8.

18 Shires GT, Peitzman AB, Albert SA et al. Response of extravascular lung water to intraoperative fluids. Ann Surg 1983; 197: 515-8.

19 Zarins $C K$, Rice CL, Peters RM, Virgilia $R W$. Lymph and pulmonary response to isobaric reduction in plasma oncotic pressure in baboons. Circ Res 1978; 43: 925-30.

20 Kramer GC, Harms BA, Gunther RA, Renkin EM, Demling $R H$. The effects of hypoproteinemia and blood-to-lymph fluid transport in sheep lung. Circ Res 1981; 49: 1173-80.

21 Guyton $A C$. Lindsey $A W$. Effect of elevated left atrial pressure and decreased plasma protein concentration on the development of pulmonary edema. Circ Res 1959; 7 : $649-57$.
Résumé

D'aucuns ont rapporté des perturbations hémodynamiques lors du clampage de l'aorte abdominale sans mesurer cependant la quantité de liquide interstitiel pulmonaire (EVLW). Neuf patients subissant une résection élective d'anévrysme aortique ou un pontage aorto-bifémoral ont été choisis pour cette étude. On leur installait d' abord un cathéter intra-artériel et un de type Swan-Ganz puis ensuite un cathéter d'Edwards pour mesure de l'EVLW par l'artère humérale ou axillaire. On mesurait alors l'EVLW juste avant et cinq minutes après le clampage aortique et aux 30 minutes par la suite, jusqu'à la fin de l'intervention. Les valeurs de départ de l'EVLW allait de 7 à $9 \mathrm{ml} \cdot \mathrm{kg}^{-1}$ Nous $n$ 'avons pas noté de changement significatif des variables hémodynamiques non plus que de l'EVLW lors du clampage aortique et cette dernière variable est demeurée stable pendant l'intervention, tout comme la pression capillaire pulmonaire. On a par ailleurs noté une disparition des pouls en aval du site d'insertion du cathéter à EVLW sans manifestation ischémique cependant, mais un autre patient a du subir une thrombectomie axillaire. Ce taux de complication disqualifie donc les artères humérales et axillaires comme voie d' entrée pour le cathéter d EVLW. 